\title{
PRINCÍPIOS ÉTICOS PROFISSIONAIS DOS (AS) ASSISTENTES SOCIAIS: DESAFIOS NOS PROCESSOS DO TRABALHO PROFISSIONAL
}

\author{
ETHICAL PRINCIPLES OF PROFESSIONAL (AS) SOCIAL WORKERS: \\ CHALLENGES IN THE PROCESS OF PROFESSIONAL WORK
}

Cacildo Teixeira de Carvalho Neto ${ }^{1}$; Ubaldo Silveira ${ }^{2}$; Helen Barbosa Raiz Engler ${ }^{3}$

\begin{abstract}
RESUMO
O presente artigo traz uma reflexão teórica a partir do resultado de pesquisa da dissertação apresentada para a Faculdade de Ciências Humanas e Sociais, UNESP campus Franca/SP em 2013, com o título "Ética, ética profissional e o trabalho profissional do assistente social". O texto objetiva-se em apresentar os desafios para a materialização dos princípios éticos presentes no Código de Ética de 1993 dos assistentes sociais. O estudo traz como percurso metodológico a pesquisa de tipo bibliográfica e como técnica de pesquisa a revisão de literatura. A construção teóricaestá sustentada a partir da apreensão empírica dos sujeitos de pesquisa. Destaca-se que os desafios aqui apresentados não esgotam àqueles apresentados no cotidiano profissional, pois considera-se que é no cotidiano que há o processo de produção e reprodução das relações sociais em seu conjunto.
\end{abstract}

Palavras-chave: Desafios. Ética. Serviço Social. Valores.

\section{ABSTRACT}

This paper presents a theoretical reflection from the search results of the dissertation submitted to the Faculty of Humanities and Social Sciences, UNESP campus Franca / SP in 2013, entitled "Ethics, professional ethics and professional work of the social worker." The text aims on presenting challenges to the realization of the ethical principles underpinning the Code of Ethics 1993 Social Workers. The study brings as methodological approach to bibliographic search type and search technique as the literature review. The theoretical construction is supported from the empirical understanding of the subjects. It is noteworthy that the challenges presented here do not exhaust those presented to professional practice, since it is considered that there is in the daily process of production and reproduction of social relations as a whole.

Keywords: Challenges. Ethics. Social Work. Values.

\footnotetext{
${ }^{1}$ Mestre em Serviço Social e doutorando pela Faculdade de Ciências Humanas e Sociais, UNESP campus Franca/SP. Assistente Social do Mario Palmério Hospital Universitário. E-mail: cacildoneto37@gmail.com

${ }^{2}$ Doutor em Serviço Social. Assistente Social e Filósofo. E-mail: ubaldosilveira@hotmail.com

${ }^{3}$ Livre-docente do programa de Pós-graduação em Serviço Social da Faculdade de Ciências Humanas e Sociais, UNESP campus Franca/SP. E-mail: helenraiz@hotmail.com
} 


\section{INTRODUÇÃO}

Entre tensões - avanços e retrocessos -, o Serviço Social apresenta-se com arcabouço teórico-metodológico e ético-político recrudescido diante da própria sociedade, alicerçado em sua própria historia repleta de contradições, lutas, resistências e persistências; a profissão encontra-se legitimada diante da história da sociedade e em conjunto com a classe trabalhadora conduz a luta social pelos princípios éticos e políticos que sustentam sua proposta de emancipação política e humana.

Os desafios éticos presentes para a profissão neste período histórico, meados da segunda década do século XXI, são apresentados paralelamente às demandas sociais dos usuários; seja na despolitização dos direitos sociais; na precarização do trabalho; no enfraquecimento dos órgãos representativos da classe trabalhadora e órgãos de direitos (conselhos e sindicatos). Essas manifestações expressam a forma coletiva de como os desafios éticos podem ser apreendidos.

Mas outros desafios emergem neste contexto, como a própria efetivação dos princípios éticos presentes no Código de Ética de 1993. Diante de embates ídeo-políticos, a institucionalização do Serviço Social e a precarização das formas de implementação das políticas sociais públicas, o assistente social está em constante enfretamento na legitimação de um projeto societário emancipatório.

Dos desafios apresentados pelos sujeitos de pesquisa para a materialização dos princípios do Código de Ética profissional, fonte desta análise bibliográfica, pontuaremos de forma ampla alguns deles, como: os direitos sociais negados;baixa qualidade no atendimento ao usuário dos serviços sociais; as barreiras de ir além da demanda imediata e o acompanhamento ao usuário; as relações de poder institucional; a participação da categoria nos espaços de debates; a permanência do conservadorismo na profissão;o processo de formação profissional;dificuldades em interpretar o Código de Ética; e, as inflexões da sociedade capitalista neoliberal.

\section{DESENVOLVIMENTO}

Os processos de trabalho profissional do assistente social (IAMAMOTO, 2006) são mediatizados por realidades, que se materializam como demandas que emergem da sociedade e para respondê-las é exigido do profissional diferentes alternativas e/ou estratégias. Essas 
demandas são manifestações que se apresentam no cotidiano e que na própria cotidianidade há a possibilidade de transformação.

O Serviço Social inserido na divisão social e técnica do trabalho é partícipe da construção da realidade. Movido por fatores endógenos e exógenos articula propostas interventivas e ídeo-políticas projetando uma direção social aos assistentes sociais, a classe trabalhadora e a outros sujeitos que compartilham dessa mesma direção.

$\mathrm{O}$ assistente social, como trabalhador assalariado, vive continuamente as refrações do capital imprimidas como perversidade e barbárie, precarização das formas materiais e subjetivas do trabalho e desmantelamento das garantias legais promulgadas para atender a classe trabalhadora. Com sua ação institucionalizada, desenvolve seu trabalho diante do compromisso ético-político da profisssão, articulando-o aos interesses da instituição, digladiando ou não aos interesses majoritários do capital. Pois o trabalho profissional reproduz tanto os mecanismos de exploração e reprodução do capital, como também às respostas as necessidades da população usuária (IAMAMOTO, 2008a).

O trabalho profissional realizado no cotidiano objetiva-se ao emergir como resultado da práxis, como trabalho não só interventivo, mas também ídeo-político. O produto desse trabalho, ação primária da práxis social, é composto por elementos que consubstanciam a competência e compromisso profissional, tais como os técnico-operativos, teóricometodológicos e ético-políticos. Apreender esse movimento é compreendê-lo nas ações concretas desenvolvidas pelos assistentes sociais (FORTI, 2010) e nos debates políticos da categoria (BARROCO, 2012).

Em seu processo de trabalho, o assistente social depara-se com constantes desafios para a materialização dos princípios éticos do Código de Ética profissional. Esses desafios estão presentes no cotidiano profissional, como explicitado, assim como as respostas profissionais.

Os processos de trabalho dos sujeitos de pesquisa têm como sujeitos de intervenção, usuários dos serviços sociais, que em sua maioria encontra-se com seus direitos negados, ou estão em busca de acesso a esses direitos que são desenvolvidos por meio de políticas, programas e projetos sociais. $\mathrm{O}$ assistente social é chamado para intervir em situações em que os usuários encontram-se em situação de risco e vulnerabilidade social.

A busca por direitos marca os processos de trabalho da profissão, assim como as formas de acesso. Mas além de desenvolver suas atribuições e competências, o assistente social tem o compromisso de que o acesso e permanência dos usuários nas políticas, 
programas e projetos sejam de qualidade. Não retrocedendo ao viés messiânico e ou fatalista de tomar para si a responsabilidade do processo, uma vez que esses serviços são multiprofissionais, e com isso formados por diversos projetos profissionais.

As necessidades pelos serviços sociais demandados pelos usuários do Serviço Social estão além da necessidade do Eu, pois se tornou coletiva, há a massificação da desigualdade socioeconômica e suas injunções imprimem à população subalterna, estando essa parcela da população na classe trabalhadora, as formas precárias e naturalizadas da falta de acesso aos direitos sociais como saúde, habitação, educação, entre outros. Com isso, tais necessidades materializam-se na forma de pobreza e criminalização, depositado nessa população a responsabilidade pela desordem social, a responsabilização pela atual conjuntura deficitária e o não acesso aos bens e riqueza socialmente produzidos, a moralização da questão social.

O assistente social, ao avançar das formas imediatas como tais necessidades se manifestam, articulando ao conhecimento acumulado e sua competência e compromisso, está realizando a mediação entre a singularidade e a universalidade, sendo esta última representada pelas leis tendenciais, tais como apresentadas nas políticas sociais, criando a possibilidade de alcançar a particularidade do contexto ao qual o usuário está imerso.

O profissional cria possibilidades de articular e desenvolver seu trabalho de forma que alcance a totalidade, rompendo com as formas abstratas de materializar os princípios éticos que compõe seu projeto profissional, manifestadas apenas na intencionalidade, apenas no plano ideal (FORTI, 2010), pois a ética profissional objetiva-se nas ações profissionais concretas articuladas com direção ídeo-política da profissão (BARROCO, 2008).

Para alcançar ações concretas nos processos de trabalho é relevante o acompanhamento do profissional ao usuário.

$\mathrm{O}$ assistente social tem o direito de manter contato direto com a população usuária, junto aos seus locais de moradia e de organização, o que permite estabelecer vínculos com os seus movimentos e apreender as suas demandas. $\mathrm{O}$ assistente social detém informações, tem conhecimento sobre os programas que devem ser postos a serviço dos usuários, reforçando o seu poder reivindicatório junto às instituições responsáveis pelas políticas e programas. (BARROCO, 2012, p. 83)

O acompanhamento permite que o profissional estabeleça vínculo junto ao usuário, avançando para além da demanda imediata. Esse vínculo permite ainda a aproximação do usuário a outros espaços deliberativos como conselhos e fóruns, o que promove a participação dos usuários nas decisões deliberadas nesses espaços. 
Nas relações estabelecidas entre o assistente social e o usuário, formadas no cotidiano profissional, é necessário identificar o limite profissional para que as ações não sejam impositivas ao usuário, cerceando-o de sua liberdade de escolha. Os profissionais que não reconhecem esse limite avançam para além da privacidade e liberdade de escolha dos usuários, reproduzindo os interesses institucionais, classistas e ou da própria categoria profissional. Pois, "A objetivação ética do compromisso profissional com os usuários supõe uma postura responsável e respeitosa em relação às suas escolhas, mesmo que elas expressem valores diversos dos valores pessoais do profissional." (BARROCO, 2012, p. 87).

As refrações do trabalho profissional rebatem diretamente no produto do seu trabalho e juntamente nas possibilidades de legitimação dos direitos dos usuários envolvidos nesse contexto, reproduzindo a precariedade dos serviços e acesso aos direitos, Barroco (2012, p. 80-81) explicita que "A rotina cotidiana oculta diferentes faces do desrespeito sofrido pelos usuários nas triagens, nas entrevistas, nas idas e vindas em várias instituições, até ser atendido, na invasão de sua privacidade, na moralização de suas atitudes."

A relação de poder que se estabelece nas intermediações entre instituições, usuários e assistentes sociais é reflexo de um solo culturalmente construído sob os interesses do poder. $\mathrm{O}$ poder econômico está intimamente ligado com o poder político, e esse com o poder social, que está conectado ao poder econômico, formando uma tríade de interesses compartilhados aos ditames do capital, ao mesmo tempo contraditória.

A análise realizada demonstra que os valores éticos profissionais presentes no cotidiano vão de encontro às condições materiais e ídeo-políticas das instituições, reafirmando o embate entre os projetos sociais que se formam nas relações sociais (econômicas, políticas e culturais) e também nas contradições das relações de trabalho.

Esta tensão remete ao que eu, enquanto assistente social, posso e quero fazer - logo, refere-se ao meu desejo e à minha adesão aos compromissos profissionais - , e por outro lado, àquilo que devo fazer como algo parametrado coletivamente pelo projeto ético-político da categoria. (PAIVA; SALES, 2003, p. 179).

Compreende-se que é no campo das tensões que o assistentes social avança para uma direção social contrária ao posicionamento hegemônico neoliberal. Momento que emergem as mediações repletas de intencionalidades, compromissos e coletividade, ações práticas e políticas no campo da totalidade, pois a ética permeia todas as relações em que o homem está presente e nela desenha sua história. 
Nesse solo fértil de possibilidades o assistente social desenvolve suas habilidades e competências visando uma direção coletiva, pois seu trabalho tem a possiblidade de extrapolar o individualismo liberal, alcançando os sujeitos coletivos.

Compreender que a materialização dos princípios éticos só é possível se apreendidos e absorvidos de forma coletiva, demonstra uma visão de que o projeto profissional em construção requer a participação de todos os sujeitos, pois sua legitimação "[...] não depende somente da categoria profissional, mas do conjunto das forças sociais democrático-populares." (BARROCO, 2006, p. 207-208). A relevância em compartilhar essa construção é a de legitimar a profissão e seus princípios nos espaços coletivos, tecendo no cotidiano estratégias e possibilidades que avancem para além da imediaticidade das demandas sociais; articulando com outros sujeitos e projetando a profissão para o debate político.

Mas diante a apreensão dos sujeitos de pesquisa, apontam que a materialização dos princípios éticos do Código em vigência ainda não são totalmente materializados, devido a permanecia do conservadorismo na profissão. Paulo Netto (2008, p. 156), ao refletir sobre o projeto profissional em construção, orienta:

[...] a ruptura com o quase monopólio do conservadorismo no Serviço Social não suprimiu tendências conservadoras ou neoconservadoras, a heterogeneidade própria dos corpos profissionais propicia, em condições de democracia política, a existência e a concorrência entre projetos diferentes.

Os diferentes caminhos ídeo-políticos assumidos pelo corpo profissional brasileiro reafirma os desafios para a materialização dos princípios ético-políticos profissional, assim como a efetivação de um projeto profissional realmente hegemônico. Tal direção não está presente apenas no campo teórico e ideológico, mas na materialidade do trabalho profissional, nos desafios apresentados aos profissionais nas condições objetivas e subjetivas do trabalho.

Esses desafios presentes nos processos de trabalho do assistente social devem ser elucidados desde o processo de formação profissional, pois esse é o primeiro momento de aproximação dos valores ético profissionais com os futuros assistentes sociais. Momento em que os valores pessoais dos sujeitos (alunos) são deparados com os princípios ético-políticos profissionais. Assim, "A materialização do Código de Ética supõe uma capacitação que se inicia durante a formação profissional, nos cursos de graduação, estendendo-se para outros estágios." (BARROCO, 2012, p. 101). 
As reflexões dos sujeitos de pesquisa apontam para a ética como elemento transversal no processo de formação, perpassando todas as disciplinas, não sendo específica para uma única.

A ética está presente e deve ser evidenciada em todos os momentos da profissão, desde a formação aos processos de trabalho, constituindo a construção das competências profissionais e habilidades diante do processo mutável que se move a realidade.

A ética não se esgota numa única forma de trabalho e formação, ela está compreendida nas mediações que emergem nas histórias das sociedades, como momento de reflexão e ação concreta, prática. Sua aproximação às profissões condensa as relações de trabalho de possibilidades e compromisso ético-político com a humanidade. A direção da ética na atual sociabilidade apresenta-se por vieses diferentes. Ela pode ser utilitária ao corporativismo e suas formas unilaterais de ação voltada ao interesse privado; ter um cariz humanista com direção social ao coletivo; ser fonte de reprodução para as formas ideológicas do capital.

Diante do exposto, e como bem apresentado pelos sujeitos de pesquisa, os assistentes sociais tem que interpretar o código, desvelar os valores e fundamentos nele contidos. Aguiar (2003, p. 118) elucida que,

[...] é preciso saber traduzir, na prática, as estratégias para a viabilização deste compromisso, uma delas está no conhecimento filosófico como ponto de partida para a compreensão da origem dos determinantes políticos, sociais e econômicos, pois implicam intencionalidades e, estas, ética e valores.

Os limites e desafios éticos apresentados aos assistentes sociais se acentuam com as relações institucionais, como citado anteriormente, pois os órgãos contratantes desses profissionais podem não compartilhar da direção social tratada no projeto político da categoria. Tão como heterogêneo é a própria profissão, os projetos profissionais que se mesclam na sociedade têm vertentes diferentes, compondo assim uma multiplicidade de projetos sociais e profissionais.

Os organismos contratantes exigem do profissional conhecimento generalista, constante aprimoramento intelectual e tecnológico, criatividade, eficácia e eficiência. A constante capacitação profissional é responsabilidade ética traduzida no Código em estudo como um dos princípios fundamentais. A capacitação e ou formação continuada permite que os assistentes sociais estejam próximos dos debates atualizados da categoria e outras políticas.

Em meio às tensões e resistências, os assistentes sociais, compondo a classe trabalhadora, são peças do xadrez, soldados que o capital avança ou elimina do tabuleiro da sociedade, reproduzindo os interesses e mantendo as relações de produção para o consumo 
extremo. Pois, ao mesmo tempo em que a direção social orquestrada pela categoria profissional projeta as formas objetivas e subjetivas para o trabalho profissional, essa categoria produz e reproduz os interesses do capital e suas formas de produção material.

Considerar tais prerrogativas não é negar a autonomia (relativa) do profissional e sua possibilidade de mudar as relações que transitam no cenário de trabalho. Das competências e compromissos que mobilizam a categoria profissional e exige estratégias para os processos de trabalho, a autonomia mesmo que relativa, tenciona as ações profissionais no campo dos limites e possibilidades.

A autonomia profissional prevista no Código de Ética deve compor os valores que os profissionais coadunam cotidianamente nos processos de trabalho, reafirmando os valores esboçados no projeto profissional, materializados nas mediações profissionais.

Ao tecer as considerações dos sujeitos de pesquisa, foi explicitado sobre o desafio de projetar outra sociedade, como citado anteriormente. Mas é relevante destacar que todos os sujeitos de pesquisa, ao serem questionados sobre o desafio para a materialização dos princípios éticos do Código de Ética e com isso sua projeção para o projeto ético-político, elencaram que a atual sociedade capitalista neoliberal é o maior desafio.

A sociedade capitalista, a partir da política-econômica neoliberal adotada no século XX, especificamente no Brasil, acentuou nas relações sociais a contraditoriedade eminente desse sistema. O capitalismo imprimiu na sociedade seus valores e perspectivas reproduzindo nas classes sociais sua ideologia; estrutura e superestrutura consubstanciam os interesses majoritários do capital.

No mundo do trabalho (ANTUNES, 2006), as refrações da política econômica neoliberal massificaram de forma precisa as desregulações das políticas para a classe trabalhadora, orquestrou os avanços tecnológicos e a desproletarização ${ }^{1}$ a subproletarização ${ }^{2}$ dessa classe.

A atual sociabilidade é conduzida por valores antagônicos, projetos sociais distintos que se chocam, por serem compostos por classes sociais. Várias mediações são impulsionadas, outras retraídas, movem-se no cotidiano e nele compõe a realidade complexa e contraditória. "Os projetos societários constituem estruturas flexíveis e cambiantes: incorporam novas demandas e aspirações, transformam-se e se renovam conforme as conjunturas históricas e políticas." (PAULO NETTO, 2008, p. 143).

Recorre-se a Guerra (2007, p. 9) para compreender o projeto neoliberal e a perspectiva do capitalismo: 
No momento atual, o projeto neoliberal, que é o projeto do grande capital, o qual almeja suprimir tudo o que limita o livre desenvolvimento/valorização do capitalismo, tem sido a proposta que sustenta os processos de privatização e mercantilização da vida social no capitalismo tardio. Para tanto, o neoliberalismo tem investido no enfraquecimento dos movimentos sociais, trabalhistas, sindicais, de modo que sua ascensão vem em razão direta à regressão e fragilidade das formas de organização dos trabalhadores via sindicatos, partidos e outras instituições democráticas.

O viés adotado pelo projeto neoliberal destaca as inflexões do capitalismo e as formas (des)regulatórias para a classe trabalhadora. Formando um cenário de resistência e rebeldia, a classe trabalhadora é desafiada a articular novos projetos, compostos por sujeitos coletivos, representam a correlação de forças que se moldam numa direção social de interesses e ações, pois ideológico e político, permite um conjunto de mediações.

O assistente social, como integrante da classe trabalhadora, presencia todas as transformações na sociedade brasileira nos últimos 70 anos. Experimenta as inflexões e injunções do capitalismo e suas formas de coerção e consenso. Mobilizada e reorganizada, a categoria profissional nos últimos 30 anos, articula novas propostas de trabalho, adotando uma nova postura diante da realidade e a sociedade, avançando no fundamento teóricometodológico, técnico-operativo e ético-político compondo assim um projeto ético-político profissional com uma direção social definida.

Os projetos profissionais representam o conjunto de valores, diretrizes éticas e políticas, conhecimento teórico, referencias metodológicas que postulam a direção social de determinada categoria (GUERRA, 2007). No Serviço Social, o projeto ético-político (PEP) está em construção desde meados da década de 1960, concomitante ao Movimento de Reconceituação, e que num processo de renovação mobilizou a categoria e órgãos representativos na edificação dos parâmetros legais que sustentasse a direção social que se construía.

Formado por valores éticos e políticos, por diretrizes e metodologias que condensam as competências profissionais, e regado de historicidade e consciência crítica frente a realidade e suas manifestações, o PEP representa um conjunto de intencionalidades, propostas e intervenções que compõe as mediações realizadas nos vários espaços de atuação profissional e de movimento político.

Num contexto de aproximações sucessivas, o trabalho profissional é posto diante dos limites e possibilidades de desenvolver ações que permitam avançar a imediaticidade, ultrapassando as barreiras organizacionais e legais. 
O projeto profissional apresenta uma correlação de forças que são esteadas na própria história da sociedade e na luta de classes. Não homogêneo, mas hegemônico, está alicerçado em pressupostos teóricos, metodológicos, éticos, políticos, ideológicos, técnicos e operativos, que esboçam o conjunto dos valores e direção social da maioria dos profissionais.

O PEP do Serviço Social é considerado como projeto societário, pois apresenta como finalidade a emancipação política da sociedade, ou seja, não traz em seu cariz político apenas intenções e intervenções para a categoria, mas sim para toda a sociedade. Abramides (2007, p. 36) destaca:

O projeto profissional se vincula a projeto societário emancipatório ancorado em instrumentos jurídicos, expressão das referências teórico-metodológicas e ético-políticas, que sustentam a direção sociopolítica do projeto de formação e exercício profissional que se encontra alicerçado nas determinações sóciohistóricas da realidade.

O desafio de legitimar o PEP torna-se ainda maior ao projetá-lo nessa amplitude que se almeja. Relevante destacar que é nos desafios que as propostas são elucidadas, assim nesse emaranhado de limites encontra-se o celeiro do conhecimento e do compromisso profissional, regado de possibilidades e desejos de avançar num processo contínuo e infindável de transformações, e o desejo de amanhecer numa outra sociabilidade numa direção ética realmente humana.

\section{CONSIDERAÇÕES FINAIS}

Anunciar o trabalho profissional e a materialização dos princípios éticos é reconhecer que esse movimento é repleto de desafios, pois os princípios elencados no Código de Ética profissional de 1993 trazem em seu bojo valores humanistas e um caráter político de cunho contra-hegemônico aos denodos do capital.

A materialização dos princípios éticos profissionais está no próprio cotidiano profissional, seja nas intervenções, mediações e debates políticos, como também no processo de formação profissional. Nos últimos 30 anos a profissão vem articulando novas posturas diante a realidade social, mesclando intencionalidade a ações concretas, produzindo um novo caminho para a efetivação dos direitos sociais, para a emancipação política, criando estratégias para uma nova sociabilidade.

Regado de um acúmulo teórico-metodológico e técnico-operativo, o cariz éticopolítico que se consubstancia na profissão representa uma nova dimensão, oposta ao 
conservadorismo e ao tradicionalismo que alimentaram a perspectiva profissional em suas protoformas. O Código de Ética profissional representa na atualidade um aporte legal para o enfrentamento das expressões da questão social, suas formas materiais e espirituais, que se manifestam na realidade.

\section{NOTAS}

1- Desproletarização: substituição do trabalho humano pelo tecnológico (máquinas).

2- Subproletarização: o trabalhador enquanto exercito industrial de reserva

\section{REFERÊNCIAS}

ABRAMIDES, Maria Beatriz Costa. Deafios do Projeto Profissional de ruptura com o conservadorismo. Serviço Social \& Sociedade, São Paulo, ano 28, v. 91, p. 34-48, set. 2007.

AGUIAR, Sandra Maria Zanello de. A presença da ética como compromisso ético-político na formação profissional do assistente social. Revista Capital Científico, Guarapurava, v. 1, n. 1, p. 115-122, jan./dez. 2003. Disponível em:

<www.revistas.unicentro.br/index.php/capitalcietífico/article/.../597/733>. Acesso em: jan. 2013.

ANTUNES, Ricardo. Adeus ao trabalho?: ensaio sobre as metamorfoses do mundo do trabalho. São Paulo: Cortez, 2006.

BARROCO, Maria Lucia Silva. Ética e Serviço Social: fundamentos ontológicos. São Paulo: Cortez, 2006.

. Ética: fundamentos sócio-históricos. São Paulo: Cortez, 2008.

- Materialidade e potencialidades do Código de Ética dos assistentes sociais. In:

; TERRA, Sylvia Helena. Código de Ética do/a assistente social comentado. São Paulo: Cortez, 2012.

FORTI, Valeria. Ética, crime e loucura: reflexões sobre a dimensão ética no trabalho profissional. Rio de Janeiro: Lumen Juris, 2010.

GUERRA, Yolanda. O Projeto Profissional Crítico: estratégias de enfrentamento das condições contemporâneas da prática profissional. Serviço Social \& Sociedade, São Paulo, ano 28 , v. 91 , p. 5-33, set. 2007.

IAMAMOTO, Marilda Vilela. O Serviço Social na contemporaneidade. 10. ed . São Paulo: Cortez, 2006.

Serviço Social em tempo de capital fetiche: capital financeiro, trabalho e questão social. São Paulo: Cortez, 2008a. 
- As dimensões ético-Políticas e Teórico-Metodológicas no Serviço Social Contemporâneo. In: MOTA, Ana Elizabete. (Org.). Serviço Social e Saúde: formação e trabalho profissional. São Paulo: Cortez, 2008b.

PAIVA, Beatriz Augusto; SALES, Mine Apolinário. A nova ética profissional: práxis e princípios. In: BONETTI, Dilsea Adeodata (Org.). Serviço Social e ética: convite a uma nova práxis. São Paulo: Cortez, 2003.

PAULO NETTO, José . A construção do Projeto Ético-Político do Serviço Social. In: MOTA, Ana Elizabete. (Org.). Serviço Social e Saúde: formação e trabalho profissional. São Paulo: Cortez, 2008.

RECEBIDO EM: 13/03/2015.

APROVADO EM: 23/09/2015. 